\title{
Phagocytosis of bacterial strains isolated from acute dentoalveolar abscess
}

\author{
M. A. O. LEWIS*, S. G. MILLIGAN, T. W. MACFARLANE and F. A. CARMICHAEL $\dagger$ \\ Department of Oral Medicine and Pathology and †Department of Oral Surgery, University of Glasgow Dental \\ Hospital and School, 378 Sauchiehall Street, Glasgow G2 3JZ
}

\begin{abstract}
Summary. The phagocytosis by human polymorphonuclear leucocytes of 37 bacterial strains identified as Streptococcus milleri (10 strains), strictly anaerobic gram-positive cocci (10) Prevotella intermedia (6), Pr. oralis (5) and Fusobacterium nucleatum (6) was investigated in vitro. The ingestion of $S$. milleri and strictly anaerobic gram-positive cocci was significantly greater $(\mathrm{p}<0.001)$ than that of strains of Prevotella spp. and F. nucleatum. The degree of uptake of capsulate and non-capsulate strains did not differ.
\end{abstract}

\section{Introduction}

The microflora of acute dentoalveolar abscess usually comprises three or four bacterial species from a wide variety of genera, including facultative anaerobic gram-positive cocci, strictly anaerobic grampositive cocci and strictly anaerobic gram-negative bacilli. ${ }^{1}$ Strict anaerobes tend to predominate in the mixed flora of acute dentoalveolar abscess $;^{2}$ clinical isolates of Streptococcus milleri, strictly anaerobic gram-positive cocci, Porphyromonas and Prevotella spp. (both Bacteroides spp.) and Fusobacterium nucleatum have proved pathogenic in an animal model. ${ }^{3}$ However, the bacterial species encountered are usually regarded as members of the commensal oral flora ${ }^{4}$ and because of this it is unclear which of their potential pathogenicity factors cause abscess formation. It has been suggested that the possession of a capsule may be partly responsible for the pathogenicity of strictly anaerobic gram-positive cocci, Bacteroides fragilis and $P$. asaccharolytica. ${ }^{5}$ Capsulate strains of the $B$. fragilis group and $\mathrm{Pr}$. melaninogenica isolated from various body sites have proved to be more pathogenic than non-capsulate forms ${ }^{6-9}$ but there is little information available as regards the role of strict anaerobes isolated from orofacial abscess. Capsulate strains of strictly anaerobic gram-positive cocci and Prevotella spp. have been cultured from periapical abscess in children ${ }^{6}$ but information relating to adult infection is lacking. Since a capsule is known to protect bacterial strains from phagocytosis by host polymorphonuclear leucocytes $(\mathrm{PMNL})^{5,10}$ the aim of the present study was to examine the phagocytosis in vitro of capsulate and non-capsulate strains of the predominant bacterial

Received 5 Aug. 1992; accepted 10 Aug. 1992.

* Present address: Department of Oral Surgery, Medicine and Pathology, University of Wales College of Medicine, Heath Park, Cardiff CF4 4XY. species isolated from acute dentoalveolar abscess in adults.

\section{Materials and methods}

\section{Bacteria}

Bacterial strains were isolated from pus samples aspirated from acute dentoalveolar abscess in adults as described previously. ${ }^{2}$ The 37 isolates selected for study were $S$. milleri (10 isolates), strictly anaerobic gram-positive cocci (10), Pr. intermedia (6), Pr. oralis (5) and $F$. nucleatum (6). All isolates were lyophilised within three subcultures of primary isolation.

Lyophilised cultures were reconstituted in Anaerobic Blood Broth (Gibco) and inoculated on to Columbia Blood Agar (Oxoid) before incubation at $37^{\circ} \mathrm{C}$ in an anaerobic chamber (Don Whitley Scientific Ltd, Shipley, West Yorkshire). Purity of growth was checked and $c .40$ colonies were inoculated into $20 \mathrm{ml}$ of anaerobic blood broth before anaerobic incubation at $37^{\circ} \mathrm{C}$ for $48 \mathrm{~h}$. Subsequent cultures were centrifuged at $1000 \mathrm{~g}$ for $10 \mathrm{~min}$ and the pellets were washed and resuspended in modified Hanks's Balanced Salts Solution containing gelatin $0.1 \%$ (Gel-HBSS). The bacterial suspension was standardised spectrophotometrically to give a viable count of $1 \times 10^{7} \mathrm{cfu} / \mathrm{ml}$.

\section{Capsular staining}

The presence of a capsule was established for each isolate with Hiss's stain ${ }^{11}$ and by negative staining with India ink. ${ }^{12}$

\section{Opsonisation}

Fresh human plasma was collected from five healthy volunteers, pooled and stored in $5-\mathrm{ml}$ volumes at $-70^{\circ} \mathrm{C}$. For opsonisation $1 \mathrm{ml}$ of a bacterial sus- 


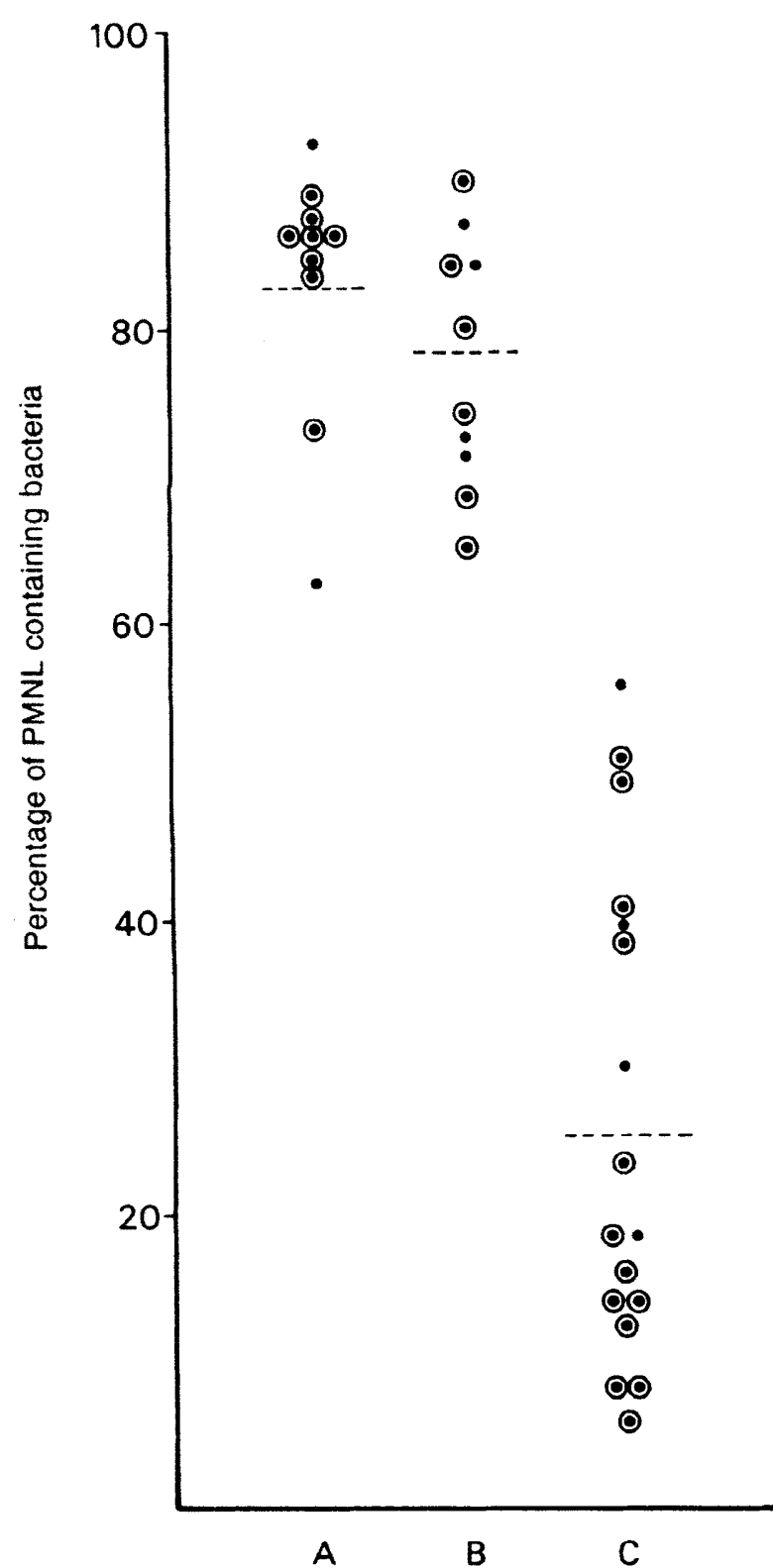

Fig. 1. The percentage of PMNL containing bacteria in phagocytic experiments with $\mathbf{A}, 10$ strains of $S$. milleri; $\mathbf{B}, 10$ strains of strictly anaerobic gram-positive cocci, and $\mathbf{C}, 17$ strains of gram-negative anaerobic bacilli-- Pr. intermedia (6), Pr. oralis (5) and $F$. nucleatum (6)-isolated from acute dentoalveolar abscess. Capsulate strain $O$; non-capsulate strain $\bullet$; mean .....

pension was mixed with an equal volume of plasma before incubation in an orbital incubator (Fison Scientific Equipment, Loughborough, Leics) at $100-$ rpm for $45 \mathrm{~min}$ at $37^{\circ} \mathrm{C}$. The preparation was then centrifuged at $1000 \mathrm{~g}$ for $10 \mathrm{~min}$ and the bacterial pellet was resuspended in $2 \mathrm{ml}$ of Gel-HBSS to produce a concentration of $5 \times 10^{6} \mathrm{cfu} / \mathrm{ml}$.

\section{Leucocyte preparation}

Heparinised venous blood freshly obtained from one of the five healthy volunteers was mixed with dextran (mol. wt $150000 ; 6 \% \mathrm{w} / \mathrm{v}$ in saline $0.85 \%$ ) and left for $30 \mathrm{~min}$ at $20^{\circ} \mathrm{C}$ to allow sedimentation of the erythrocytes. The supernate was then layered over Histopaque-1077 (Sigma Diagnostics) and centrifuged at $150 \mathrm{~g}$ for $30 \mathrm{~min}$. The leucocyte-rich pellet was

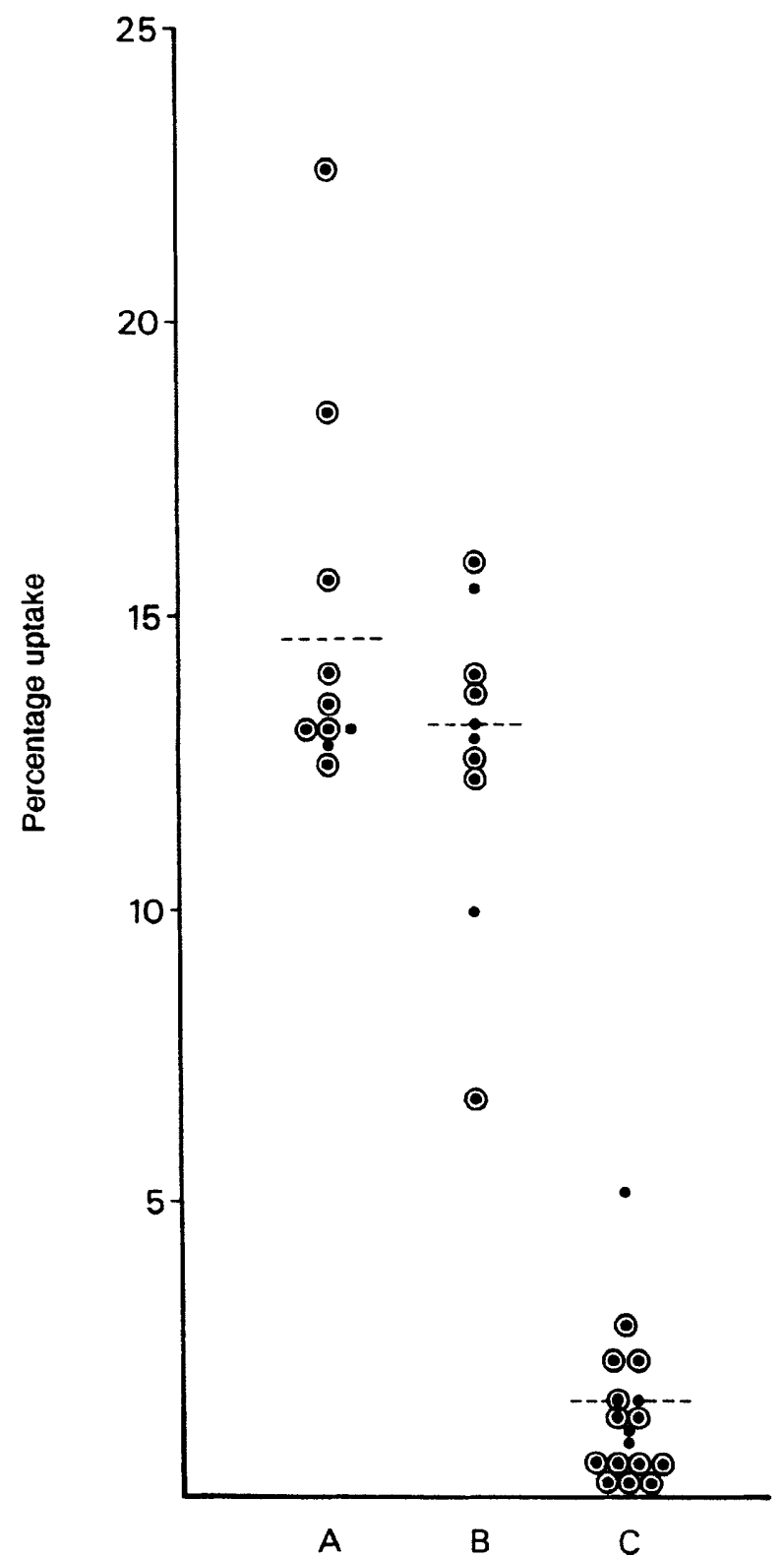

Fig. 2. Percentage uptake by PMNL of bacterial strains: A, 10 strains of S. milleri; $\mathbf{B}, 10$ strains of strictly anaerobic gram-positive cocci and C, 17 strains of gram-negative bacilli-Pr. intermedia (6), $P r$. oralis (5) and $F$. nucleatum (6) isolated from acute dentoalveolar abscess. Capsulate strain $O$; non-capsulate strain $\bullet$; mean -.--.

washed with ammonium chloride $0.87 \%$ to lyse any remaining erythrocytes. The preparation was then centrifuged at $150 \mathrm{~g}$ for $5 \mathrm{~min}$, washed and finally resuspended in Gel-HBSS at a concentration of $1 \times 10^{5}$ $\mathrm{PMNL} / \mathrm{ml}$ as determined with a haemocytometer. The viability of the PMNL was confirmed at this stage by trypan blue exclusion; ${ }^{13}$ if this was $>95 \%$ the preparation was used immediately.

\section{Phagocytosis assay}

Equal volumes $(1 \mathrm{ml})$ of opsonised bacterial suspension and PMNL suspensions were mixed and placed in an orbital incubator at $100 \mathrm{rpm}$ and incubated at $37^{\circ} \mathrm{C}$ for $45 \mathrm{~min}$.

Duplicate $100-\mu \mathrm{l}$ amounts were removed and placed on to glass slides with a Cytospin 2 cytocentrifuge 
(Shandon Scientific Ltd, Runcorn, Cheshire) set at $500 \mathrm{rpm}$ for $5 \mathrm{~min}$. Preparations were fixed and stained by Leishman's method, as for a blood film. ${ }^{14}$ Cytopreparations were examined by light microscopy and a total of 100 randomly selected PMNL were examined for the presence of bacteria. (Previous standardisation analysis had shown that a count of 100 PMNL gave reliable and reproducible results.) The number of PMNL containing bacteria (PMNL count) and the number of bacteria within the PMNL (bacterial count) were recorded. The percentage uptake of bacteria was calculated as follows.

\section{Number of PMNL in suspension $\times$} (PMNL count $/ 100) \times$

\section{$\frac{(\text { bacterial count } / 100)}{\text { Number of bacteria in suspension }} \times 100$}

Each bacterial strain was tested three times on separate occasions with a different source of PMNL in each experiment. Results were expressed as the mean of the three independent observations.

\section{Statistical analysis}

Student's $t$ test was used to assess the significance of the results.

\section{Results}

In experiments with S. milleri $63-92 \%$ (mean $83 \%$ ) of PMNL were found to contain bacteria (fig. 1) and with strains of strictly anaerobic gram-positive bacteria $65-90 \%$ (mean $78 \%$ ). Differences between these two groups of organisms were not statistically significant. The percentage of PMNL containing strictly anaerobic gram-negative bacilli was $6-56 \%$, mean $26 \%$. Statistical analyses showed that significantly fewer PMNL contained strains of strictly anaerobic gram-negative bacilli (Pr. intermedia, Pr. oralis or $F$. nucleatum) than strains of either $S$. milleri $(\mathrm{p}<0.001)$ or strictly anaerobic gram-positive cocci $(\mathrm{p}<0.001)$. There was no difference between the ingestion of capsulate or non-capsulate strains.

The percentage uptake of $S$. milleri (mean $15 \%$ ) and strictly anaerobic gram-positive cocci (mean 13\%) was similar (fig. 2), although that of strictly anaerobic gram-negative bacilli (mean $1 \%$ ) was significantly less than that of either $S$. milleri $(\mathrm{p}<0.001)$ or strictly anaerobic gram-positive cocci $(\mathrm{p}<0 \cdot 001)$. There was

\section{References}

1. Lewis MAO, MacFarlane TW, McGowan DA. A microbiological and clinical review of the acute dentoalveolar abscess. Br J Oral Maxillofac Surg 1990; 28: 359-366.

2. Lewis MAO, MacFarlane TW, McGowan DA. Quantitative bacteriology of acute dento-alveolar abscesses. $J$ Med Microbiol 1986; 21 : 101-104. no difference in the degree of uptake of capsulate strains compared to non-capsulate strains.

\section{Discussion}

The results of this study indicate that human PMNL are less able to phagocytose strains of Pr. intermedia, $P r$. oralis and $F$. nucleatum isolated from acute dentoalveolar abscess than strains of $S$. milleri or strictly anaerobic gram-positive cocci, but as it is known that the amount of serum required for opsonisation of gram-negative bacteria is greater than that for gram-positive organisms, ${ }^{15}$ this may account for differences in patterns of phagocytosis. However, it was considered that the $50 \% \mathrm{v} / \mathrm{v}$ used in the present study was adequate to opsonise the spectrum of species studied and that any differences in phagocytosis could be attributed to factors associated with the bacterial strains themselves.

The possession of a capsule may in part explain the apparent pathogenicity of bacteria isolated from orofacial infections because of the inhibition of phagocytosis by leucocytes, but in the present study no difference in phagocytosis between the 10 non-capsulate strains and 27 capsulate strains was demonstrated. A capsule may not be involved primarily in resistance to phagocytosis but could influence other activities such as functions in cells. Also, it may be that in mixed infections the capsule from one species acts synergically with a second species. Capsular polysaccharides and liposaccharides of strictly anaerobic gram-negative bacilli are known to inhibit the phagocytosis of facultative gram-positive cocci in varying degrees, ${ }^{15}$ and this phenomenon may be important in acute dentoalveolar abscess, since the microbial flora often comprises a combination of strictly anaerobic gramnegative bacilli and facultative or strictly anaerobic gram-positive cocci. ${ }^{1}$ Furthermore, strains of strictly anaerobic gram-negative bacilli isolated from acute dentoalveolar abscess have been found to enhance the pathogenicity of strains of $S$. milleri and strictly anaerobic gram-positive cocci when inoculated into animals. ${ }^{3}$ Experiments on phagocytosis in vitro to assess the differential uptake of each component of a mixture of strains of Prevotella spp. and strictly anaerobic gram-positive cocci could help to explain the behaviour of the microflora in acute dentoalveolar abscess.

The authors gratefully acknowledge the technical assistance of Mr D. Mackenzie, Oral Microbiology Unit, Glasgow Dental Hospital and School. This work was supported by Smithkline Beecham Pharmaceuticals.

3. Lewis MAO, MacFarlane TW, McGowan DA, MacDonald DG. Assessment of the pathogenicity of bacterial species isolated from acute dentoalveolar abscesses. $J$ Med Microbiol 1988; 27 : 109-116.

4. Van der Velden U, Van Winkelhoff AJ, Abbas F, De Graaff J. The habitat of periodontopathic micro-organisms. $J$ Clin Periodontol 1986; 13: 243-248. 
5. Brook I. Bacteraemia and seeding of capsulate Bacteroides spp. and anaerobic cocci. J Med Microbiol 1987; 23: 61-67.

6. Brook I. Isolation of capsulate anaerobic bacteria from orofacial abscesses. J Med Microbiol 1986; 22 : 171-174.

7. Brook I, Walker RI. Significance of encapsulated Bacteroides melaninogenicus and Bacteroides fragilis groups in mixed infections. Infect Immun 1984; 44: 12-15.

8. Brook I. Pathogenicity of capsulate and non-capsulate members of Bacteroides fragilis and B. melaninogenicus groups in mixed infection with Escherichia coli and Streptococcus pyogenes. J Med Microbiol 1988; 27: 191-198.

9. Simon GL, Klempner MS, Kasper DL, Gorbach SL. Alterations in opsonophagocytic killing by neutrophils of Bacteroides fragilis associated with animal and laboratory passage: effect of capsular polysaccharide. $J$ Infect Dis $1981 ; 145: 72-77$

10. Connolly JC, McLean C, Tabaqchali S. The effect of capsular polysaccharide and lipopolysaccharide on Bacteroides fragilis on polymorph function and serum killing. $J$ Med Microbiol 1984; 17 : 259-271.
11. Paik G. Reagants, stains and miscellaneous test procedures. In: Lennette EH, Balows A, Hausler WJ, Truant JP (eds) Manual of clinical microbiology, 3rd edn. Washington, American Society for Microbiology. 1980: 1012.

12. Lambe DW, Ferguson KP, Ferguson DA. The Bacteroides glycocalyx as visualised by differential interference contrast microscopy. Can Microbiol 1988; 34: 1189-1195.

13. Baehni P, Tsai C-C, McArthur WP, Hammond BF, Taichman NS. Interaction of inflammatory cells and oral microorganisms VIII. Detection of leukotoxic activity of a plaque-derived Gram-negative microorganism. Infect Immun $1979 ; 24$ : 233-243.

14. Duguid JP. Staining methods. In: Collee JG, Duguid JP, Fraser AG, Marmion BP (eds) Mackie and McCartney's Practical medical microbiology, 30th edn, vol 2. Edinburgh, Churchill Livingstone 1989: 38-63.

15. Jones GR, Gemmell CG. Effects of Bacteroides asaccharolyticus cells and $B$. fragilis surface components on serum opsonisation and phagocytosis. $J$ Med Microbiol 1986; 22: 225-229. 